\title{
Effect of Tunneling on Adjacent Piled Foundation in Clay
}

\author{
C.F. Leung ${ }^{1}$, C.W. Ong ${ }^{2,3}$, K.Y. Yong ${ }^{1}$ \\ 1. National University of Singapore, Singapore \\ 2. One Smart Engineering Pte Ltd, Singapore \\ 3. One Smart Engineering Pte Ltd, Malaysia \\ E-mail: ceelcf@nus.edu.sg
}

Received: 1 September 2018; Accepted: 26 September 2018; Available online: 15 January 2019

\begin{abstract}
Soil movements arising from tunnel excavation may induce severe stresses on adjacent piled foundations. This paper investigates the behavior of piles due to nearby tunneling in soft clay using centrifuge modeling technique. Centrifuge modeling has an advantage that the consolidation time of the clay under forced gravity field can be expedited significantly to study the long term performance of a pile due to tunneling. The types of piles investigated in the present study include floating pile, socketed pile and end bearing piles with different pile head conditions. The test results on the induced axial and lateral pile responses due to tunneling are presented in this paper and the implications of the findings to engineering practice are highlighted.
\end{abstract}

Keywords: Tunnel; Pile; Centrifuge modeling; Bending moment.

\section{Introduction}

Tunnel excavations are often carried out for subway construction and utilities in many urban cities worldwide. With rapid economic expansion, tunnel excavations may need to be conducted close to existing buildings. Fig. 1 shows an example in Singapore whereby tunneling has been carried out as close as $0.64 \mathrm{~m}$ from the piles supporting an adjacent high-rise building. In such very close proximity, tunneling may induce severe stresses on the piles due to soil movements arising from the tunnel excavation. The additional induced moment on the pile may cause it to break if the pile moment capacity is exceeded. In view of the above, an experimental study has been initiated to investigate the effects of tunnel excavation on nearby piled foundation in clay. Centrifuge modeling technique is employed as the prototype stresses can be correctly simulated and the consolidation of the clay can be expedited under a forced gravitational field to study the long term behavior of the pile due to tunneling. In this paper, long term refers to the state that all the pile and soil movements have stabilized. The time required to reach this state depends on the permeability of the soil. The centrifuge model setup, procedure and test results are presented in this paper. The practical implications of the findings will also be discussed.

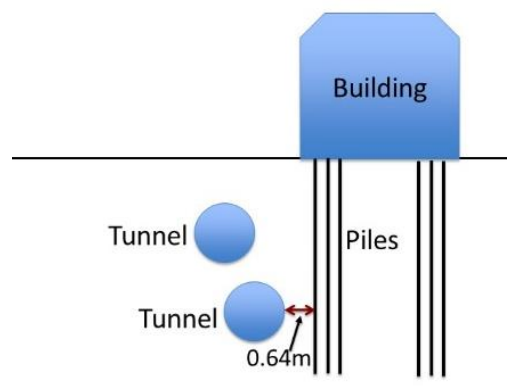

Fig. 1 Tunnel excavation carried out in very close proximity to adjacent building

\section{Centrifuge model setup and procedure}

All the centrifuge model tests were conducted on the National University of Singapore geotechnical centrifuge which has a radius of $1.8 \mathrm{~m}$ and a payload capacity of 40 g-ton [1]. Fig. 2 shows the centrifuge model setup which comprises the soil model container with a transparent front Perspex face, kaolin clay sample, tunnel assembly, instrumented piles and instruments. Sand was first rained into the model container at a constant height to achieve a consistent dense sand packing of a desired height. Clay was prepared in slurry form by mixing water to dry clay 
powder to 1.5 times liquid limit of the clay. With the underlying sand layer, the model tunnel assembly and pore pressure transducers in place inside the model container, the clay slurry was slowly poured into the model container. The clay slurry was then consolidated under a small pressure of $20 \mathrm{kPa}$ in the laboratory at $1 \mathrm{~g}$ (earth gravitational field) such that the top clay is strong enough for subsequent placement of transducers on the clay surface.

The model container was then placed on the centrifuge platform and subject to a forced gravitational field of $100 \mathrm{~g}$ till all the excess pore pressure in the clay has dissipated to achieve a normally consolidated clay strength profile. The completion of soil consolidation was verified by the pore pressure transducers placed at various locations of the clay. T-bar tests [2] were then carried out at $100 \mathrm{~g}$ to measure the undrained shear strength profile of the clay during centrifuge flight. The undrained shear strength profiles for the clay are found to be reasonably consistent for all the tests. Fig. 3 shows a typical undrained shear strength profile of the clay with the undrained shear strength increasing by about $1.5 \mathrm{~m}$ per $\mathrm{m}$ depth. As such, the strength of the normally consolidated clay is deemed soft.

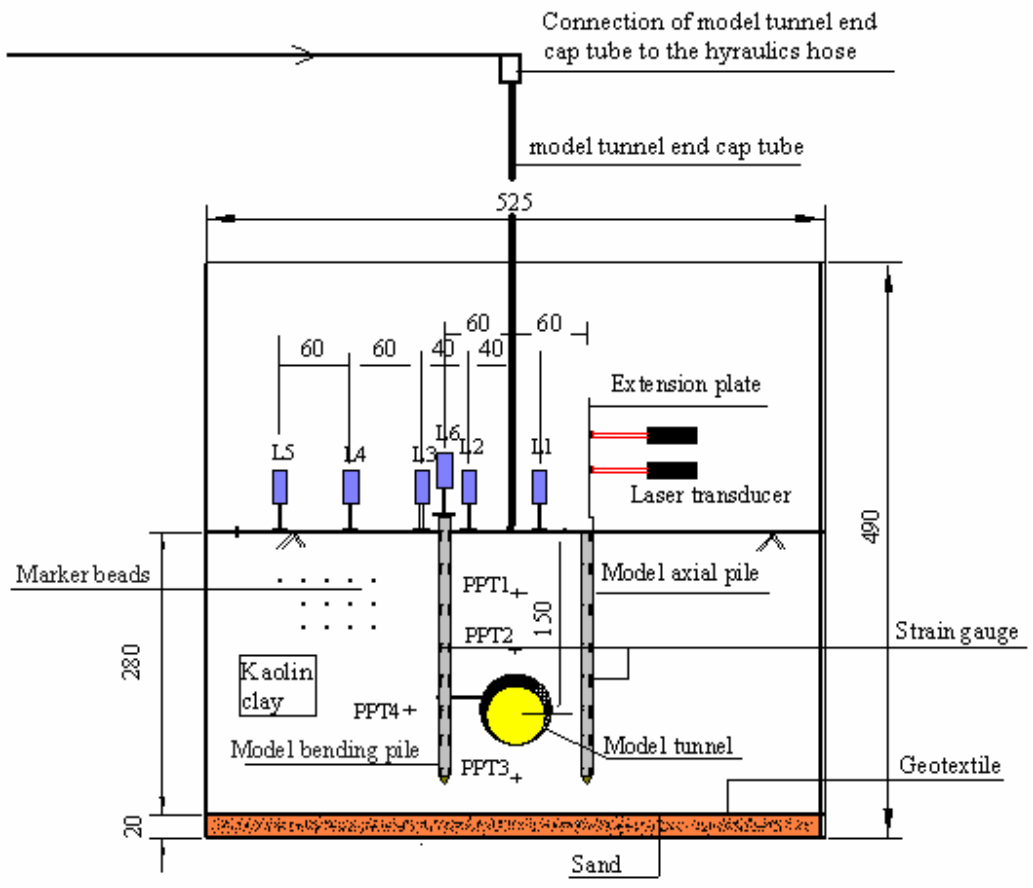

Fig. 2 Centrifuge model setup (all dimensions in $\mathrm{mm}$ )

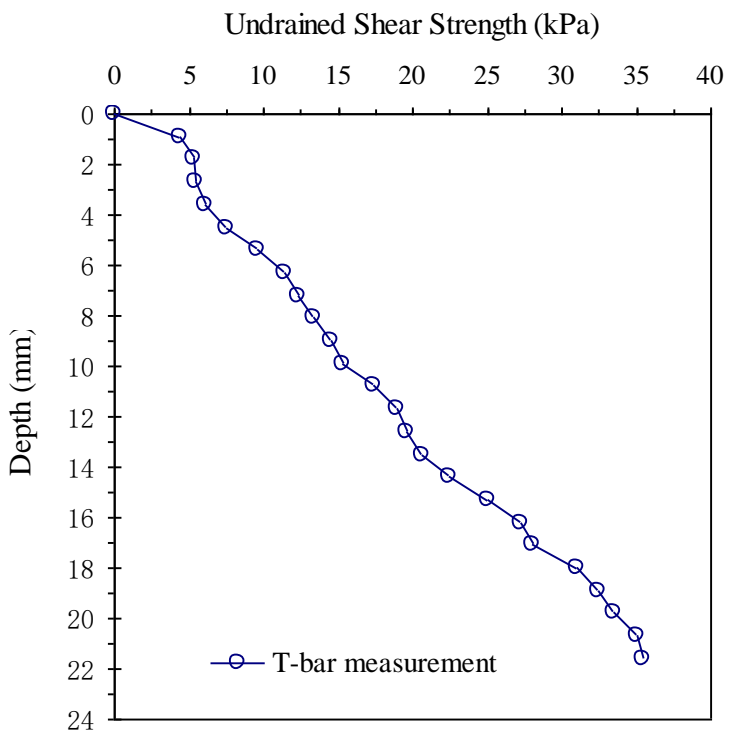

Fig. 3 Typical undrained shear strength profile of clay 
After completion of soil consolidation, the centrifuge was spun down to $1 \mathrm{~g}$. Two instrumented model piles (Fig. 4) were jacked into the clay at each side of the model tunnel at the desired distance. The piles were instrumented with strain gauges to measure the axial and lateral load transfer along the respective pile shaft, respectively. This was followed by the placement of non-contact laser transducer to measure the pile head deflection at two elevations and the placement of potentiometers to measure the pile settlement and ground surface settlement.

Once all the instrumentation was completed, the centrifuge was spun up to $100 \mathrm{~g}$ again. After the pore pressure transducers confirmed that all the excess pore pressures in the clay had stabilized, tunnel excavation began by switching on the mechanical device such that the tunnel deformation would follow the deformed shape of the tunnel shown in Fig. 2. The volume loss is 3\% for all the tests. This magnitude of volume loss is chosen as this is the desired maximum volume loss for tunnel excavation in soft clay in Singapore and in many other countries. All the instruments were monitored regularly till the readings stabilized indicating the dissipation of excess pore pressure due to tunnel excavation has been completed.
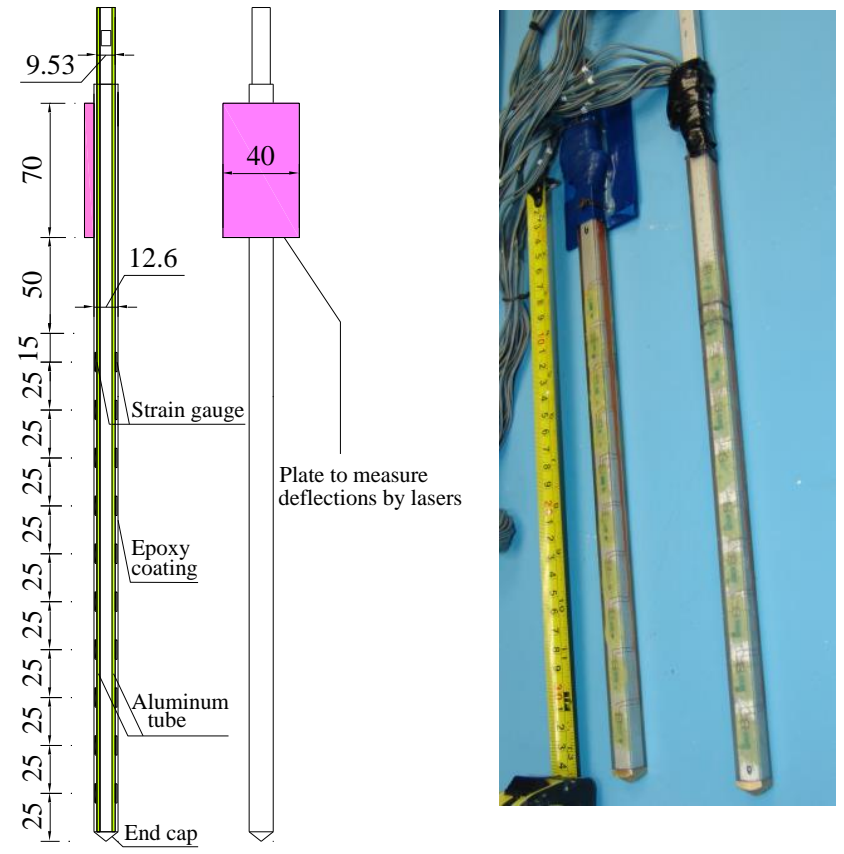

Fig. 4 Strain gauge elevations (dimensions in $\mathrm{mm}$ ) and photograph of instrumented model pile

\section{Test configuration}

Over 20 centrifuge model tests were conducted. The results of 4 tests are presented in this paper with an aim to examine the effects of tunneling on a single pile having different types of configurations. The pile types include floating piles with its base resting on soft clay, socketed piles with its lower pile shaft keyed into the underlying dense sand and end-bearing piles with its pile base resting on a hard stratum. The pile head condition of the single pile is either free or fixed. A summary of the 4 tests is presented in Table 1. Hereinafter all the dimensions and subsequent test results are presented in prototype scale following the appropriate centrifuge modeling scaling laws [3].

Table 1 Summary of centrifuge test parameters in prototype scale

\begin{tabular}{|c|c|c|c|c|c|}
\hline $\begin{array}{c}\text { Test } \\
\text { number }\end{array}$ & $\begin{array}{l}\text { Pile embedment } \\
\text { depth }\end{array}$ & $\begin{array}{c}\text { Embedment } \\
\text { depth in soft } \\
\text { clay }\end{array}$ & $\begin{array}{c}\text { Embedment depth } \\
\text { in lower dense } \\
\text { sand }\end{array}$ & $\begin{array}{l}\text { Pile head } \\
\text { condition }\end{array}$ & Pile type \\
\hline 3 & $22 \mathrm{~m}$ & $22 \mathrm{~m}$ & $0 \mathrm{~m}$ & Free & Floating pile \\
\hline 9 & $22 \mathrm{~m}$ & $19 \mathrm{~m}$ & $3 \mathrm{~m}$ & Free & Socketed pile \\
\hline 10 & $27.5 \mathrm{~m}$ & $24 \mathrm{~m}$ & $3.5 \mathrm{~m}$ & Free & End-bearing pile (resting \\
\hline 13 & $27.5 \mathrm{~m}$ & $24 \mathrm{~m}$ & $3.5 \mathrm{~m}$ & Fixed & on the hard container base) \\
\hline
\end{tabular}

Notes: For all tests, (1) Tunnel cover $\mathrm{C}=24 \mathrm{~m}$, tunnel diameter $\mathrm{D}=6 \mathrm{~m}$, tunnel volume loss $=3 \%$; (2) Clearance between pile and tunnel $=3 \mathrm{~m}$. 


\section{Lateral pile behavior}

If induced bending moment on the pile due to tunneling is large, there is a possibility that the pile may break once the ultimate pile moment capacity is exceeded. In view of this, the induced bending moment on the pile due to tunneling is examined first. Fig. 5(a) shows the induced pile bending moment profile of the 4 piles right at the stage of completion of tunnel excavation (i.e. short term) with a tunnel volume loss of $3 \%$. The induced moment profile is similar for the free head floating pile (Test 3) and free head socketed pile (Test 9). The maximum induced moment takes place around the tunnel axis elevation with the pile bending towards the tunnel as indicated by the positive bending moment magnitude. Owing to socketing into the underlying dense sand layer, the magnitude of maximum moment of the socketed pile is slightly larger than that of the floating pile. For the free head end-bearing pile (Test 10), the induced moment profile is similar to that of the floating and socketed piles. However, there is an additional pile bending curvature at the lower pile shaft with the pile bending away (negative bending moment) from the tunnel which is absent for the shorter piles. For the fixed head end-bearing pile, there is a fixed head moment at the pile top due to pile top restraint with the negative fixed head moment larger than the positive moment induced on the pile shaft close to the tunnel elevation.

During the tunnel excavation process, excess pore pressure was induced in the clay which would dissipate with time resulting in further soil movements. The instrumented piles were monitored till their readings were stabilized. It is worthy to note that at that time, the ground surface settlement had also reached its maximum magnitude and remained fairly constant after. This reveals that the soil consolidation has been completed. Fig. 5(b) shows the long term induced pile bending moment for the 4 piles. It is evident that the induced pile moments increased considerably due to increase in soil movement. The rate of increase in pile moment varies according to the pile type.

For the 3 free head piles, the maximum induced pile moment increases from about $50 \mathrm{kNm}$ in the short term to about $120 \mathrm{kNm}$ for both the floating (Test 3) and socketed piles (Test 9), and to about $150 \mathrm{kNm}$ for the end-bearing pile (Test 10) in the long term. The results reveal that the critical period for the pile bending is in the long term for free head piles due to further soil movements as the soil consolidates with the dissipation of excess pore pressure induced by tunneling. For the fixed-headed end bearing pile (Test 13), the fixed head pile moment increases from about $70 \mathrm{kPa}$ in the short term to about $160 \mathrm{kPa}$ in the long term. It is worthy to mention that the magnitude of maximum pile moment at the tunnel elevation is relatively small for the fixed head pile as compared to that of free head piles. Thus the critical elevation for induced pile moment is at the pile head. However, this is unlikely a concern as the pile cap is typically heavily reinforced.

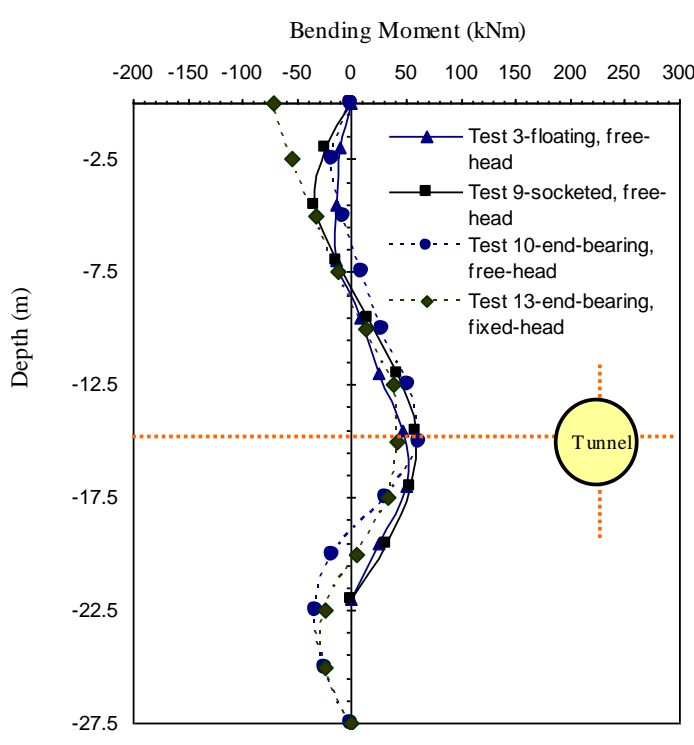

(a) Short term

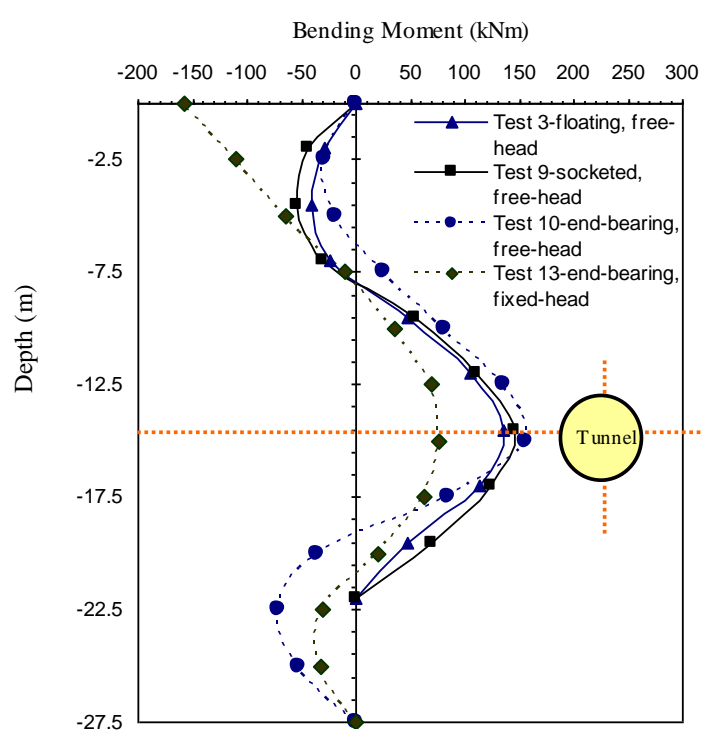

(b) Long term

Fig. 5 Induced pile bending moment profiles

The short and long term induced pile deflection profiles are next to be evaluated, see Fig. 6 . It is noted that the fixed-head end-bearing piles do not deflect much in both short and long term as the pile head is fully restraint as well as restraint by the hard stratum at the pile base. For the 3 free-head piles in the short term, the maximum pile head deflection occurs at the top, as expected, with the floating pile experiencing the largest pile head deflection due to weak restraint at the pile base. It is interesting to note that for the free head end-bearing piles, the pile shaft 
around the tunnel elevation deflects away from the tunnel. This is likely due to the restraint at the pile base. The pile top deflection of the floating pile increases significantly from about $5 \mathrm{~mm}$ in the short term to $12.1 \mathrm{~mm}$ in the long term. For the socketed pile with a stiffer restraint in the lower pile shaft, the pile head deflection increases from $2.8 \mathrm{~mm}$ in the short term to about $6 \mathrm{~mm}$ in the long term. The results reveal that although the induced moment on a floating pile is smaller than that on a socketed pile, the large pile deflection in the long term could be a concern.

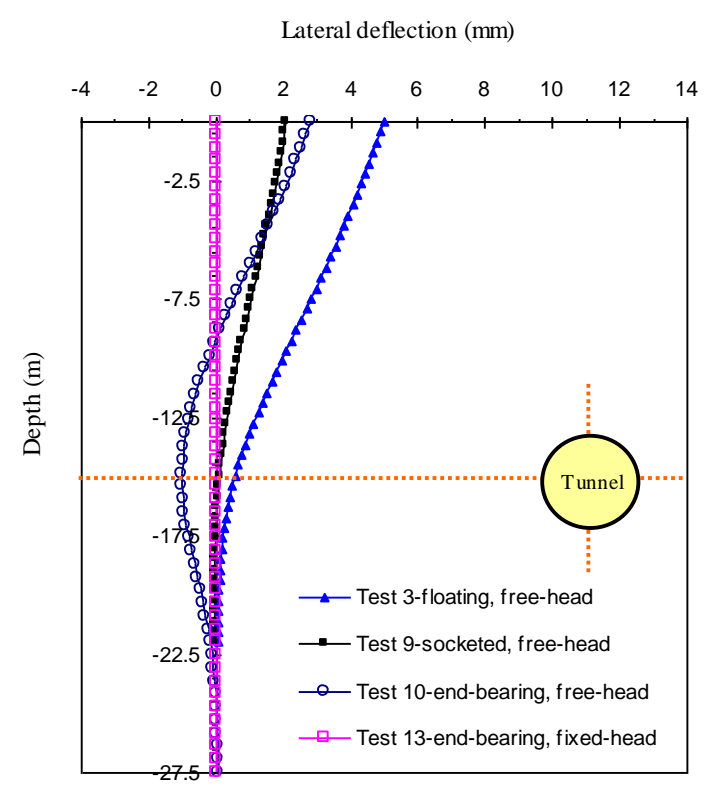

(a) Short term

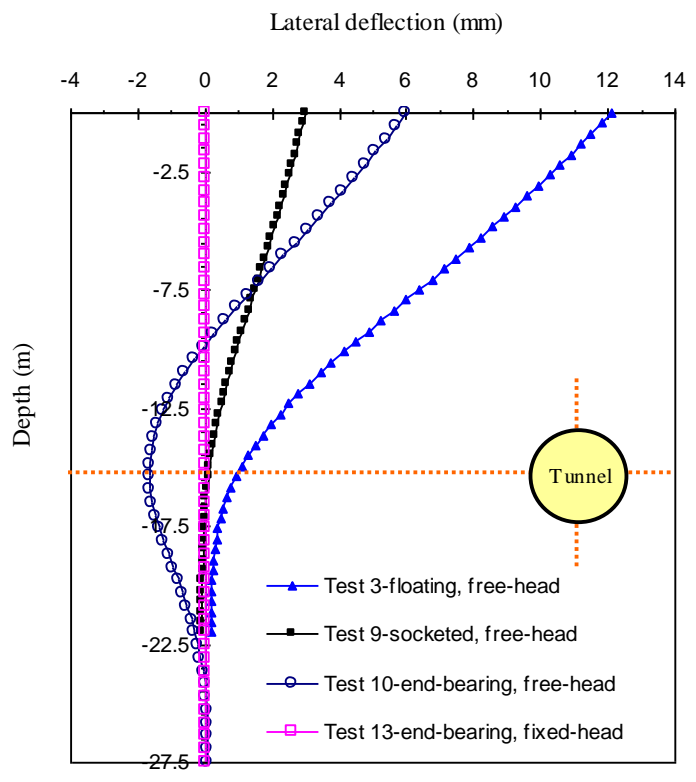

(b) Long term

Fig. 6 Induced pile deflection profiles

\section{Axial pile behavior}

The induced pile axial force profile due to tunneling is next to be evaluated, see Fig. 7. It is evident that negative skin friction has developed along all the 4 pile shafts as the induced pile axial force in all the tests increases downward beneath the pile head. However, the magnitude of negative skin friction as well as the elevation of neutral plane having zero pile load transfer varies. As expected, the largest magnitude of negative skin friction was induced on the free head end-bearing pile as the pile base was resting on a hard stratum and hence the pile base could not settle. The magnitude of maximum negative skin friction for the free-head end-bearing pile in the long term was about $800 \mathrm{kN}$ which is certainly significant. For the fixed-head end-bearing pile, tension was observed at the pile head which was prevented the pile from moving down. Similar observation has been reported in numerical studies, see for example [4]. Owing to this, the magnitude of negative skin friction for this pile is smaller than that of the free head end-bearing pile. For all cases, the magnitude of negative skin friction increases with time. As expected, the elevation of the neutral plane becomes lower in the order of floating pile, socketed pile and finally end-bearing pile. This is attributed to the magnitude of increasing soil movement along the pile shaft with a longer pile shaft experiencing more downward soil movement. It is evident that for the evaluation of pile due to tunneling in practice, engineers must evaluate whether the pile would be able to resist the negative skin friction induced due to tunneling, particularly for free-head end-bearing piles.

Table 2 shows the pile head settlement in the short and long term. The end-bearing piles do not experience any settlement as their bases are resting on the hard stratum. As expected, the floating pile experiencing the largest pile head settlement being $6 \mathrm{~mm}$ in the short time and then increasing substantially to $18.5 \mathrm{~mm}$ in the long term. As the base of the floating pile is resting on soft clay, it is easily dragged down by the settling soil. As a result, the pile head settlement increases significantly as the soil consolidates with relatively small increase in negative skin friction due to moving up of the neutral plane. The practical implication of this finding is that the settlement of a floating pile needs to be rigorously evaluated if there is tunnel excavation nearby. The corresponding pile head settlement for the socketed pile is considerably smaller, being $2 \mathrm{~mm}$ in the short term and increasing slightly to 3 $\mathrm{mm}$ in the long term. This demonstrates that the beneficial effort of pile socketed in stiff soils as the pile head settlement is unlikely a major issue. 


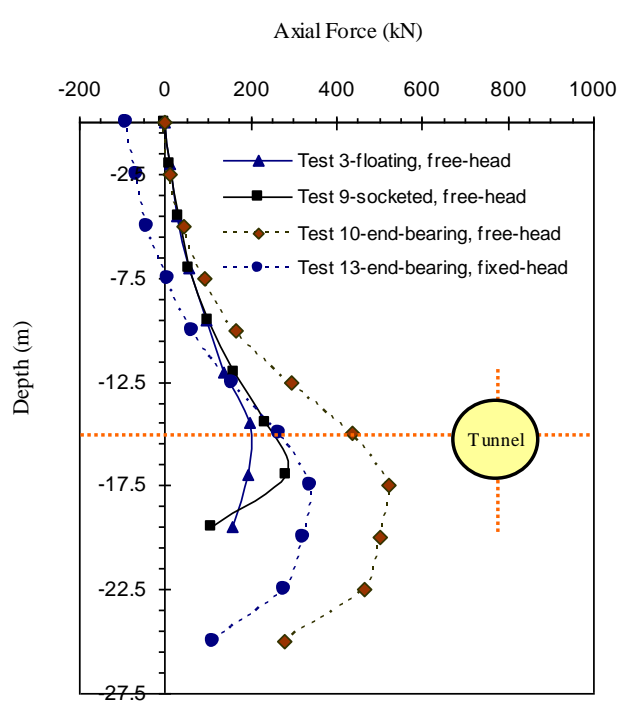

(a) Short term

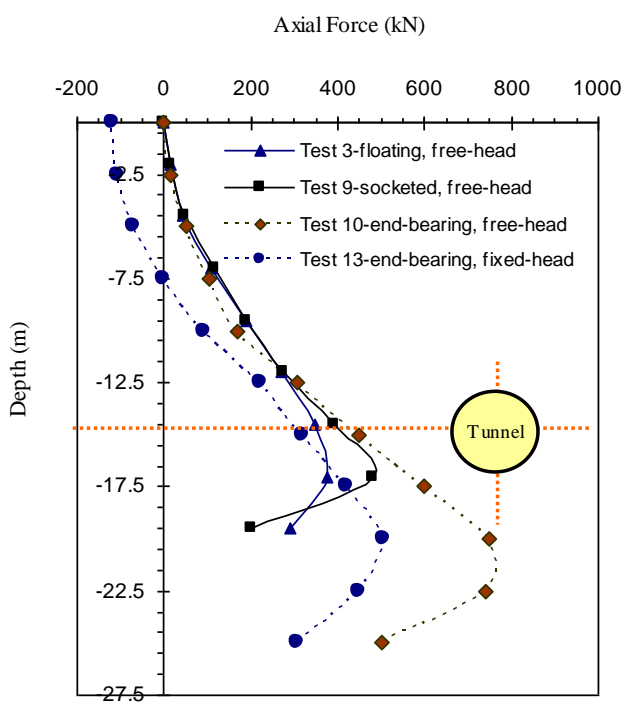

(b) Long term

Fig. 7 Induced pile axial force profiles

Table 2 Summary of induced pile head settlement (prototype scale)

\begin{tabular}{ccc}
\hline Pile number & Pile settlement (short term) & Pile settlement (long term) \\
\hline 3 & $6.0 \mathrm{~mm}$ & $18.5 \mathrm{~mm}$ \\
9 & $2.0 \mathrm{~mm}$ & $3.0 \mathrm{~mm}$ \\
10,13 & Nil pile head settlement as pile rests on hard stratum \\
\hline
\end{tabular}

\section{Conclusions}

A centrifuge model study has been carried out to investigate the axial and lateral behavior of a single pile due to nearby tunnel excavation. The results reveal that the magnitude of induced moment on a pile can be large if there is adjacent tunnel excavation. The magnitude of induced moment increases with time as the soil consolidates. For a free head pile, the critical elevation is around the tunnel elevation while for a fixed-head pile, the critical elevation is at the pile head. A free head floating pile may also suffer severe deflection at the pile head as there is little restraint at the pile base.

Negative skin friction would be induced on a pile due to tunnel excavation and the magnitude of negative skin friction increases with time till all the soil consolidation has been completed. The most critical case for negative skin friction is for an end-bearing pile as the pile could not settle and hence the neutral plane is at the pile base. On the other hand, the magnitude of induced negative skin friction on a fixed-head pile is smaller than that of free head pile due to restraint in the pile head. For a free head floating pile, the pile settlement could be a critical concern particularly in the long term as the settling soil could drag down the pile substantially as the weak soils beneath the pile base offer little resistance.

\section{References}

[1] Lee FH, Tan TS, Leung CF, Yong KY, Karunaratue GP, Lee SL. Development of geotechnical centrifuge facility at the National University of Singapore. In: Proc. Int. Conf. Centrifuge, Boulder, USA; 1991.p.11-17.

[2] Stewart DP, Randolph MF. A new site investigation tool for the centrifuge. In: Proc. Int. Conf. Centrifuge, Colorado, 1991.p.531-538.

[3] Taylor RN. Centrifuges modeling: principles and scale effects. Geotechnical Centrifuge Technology, Blackie Academic and Professional, London. 1995. p. 19-59.

[4] Mroueh H, Shahrour I. Three - dimensional finite element analysis of the interaction between tunneling and pile foundations. International Journal for Numerical and Analytical Methods in Geomechanics. 2002;26(3):217-230.

(C) 2019 by the author(s). This work is licensed under a Creative Commons Attribution 4.0 International License (http://creativecommons.org/licenses/by/4.0/). Authors retain copyright of their work, with first publication rights granted to Tech Reviews Ltd. 